\title{
Change in editors
}

\author{
Mark J. Kransdorf ${ }^{1} \cdot$ Daniel I. Rosenthal ${ }^{2}$
}

Published online: 16 November 2015

(C) ISS 2015

Beginning with the January 2016 issue, there will be some changes in the editorial leadership of Skeletal Radiology. Dr. Juerg Hodler will be replaced by Dr. Gunnar Astrom as the European editor. Dr. Mark Kransdorf continue in his role as editor for case reports, and Dr. Rosenthal will continue as chief editor.

Dr. Hodler is leaving Skeletal Radiology in order to devote more time to the activities of our parent organization, the International Skeletal Society. He has had a long tenure at Skeletal Radiology, having been appointed as editor for Europe in January 2002. During his years at the journal, there have been many changes, whereby Skeletal Radiology has grown steadily, in both size and reach. Handling almost 1, 000 submissions a year, the journal publishes more than 1 , 600 pages of articles each year, and is seen by readers in all continents except Antarctica as the result of over 2,000 individual subscriptions. Even more importantly, 9,300 institutions and 550 consortia make Skeletal Radiology available to their members. As a result of this dissemination almost 250, 000 downloads of Skeletal Radiology articles occur each year!

Very significantly, in the past 2 years, two major societies have designated Skeletal Radiology as their official journal- the Society of Skeletal Radiology (SSR) and the Australasian Musculoskeletal Imaging Group (AMSIG). We expect that these affiliations will lead to even more growth in both quality and quantity of fine articles.

During his years at the journal, Dr. Hodler has been a strong advocate of scientific rigor, assembling a team of expert reviewers from among the European supporters of the Journal. He has also been a powerful voice for publication ethics, and has lead the way in creating processes to ensure that the editors themselves avoid conflicts of interest. We wish him well in his new endeavors and look forward to many more years of his leadership at the ISS.

Dr. Gunnar Astrom, from Uppsala Sweden, is well-known to the membership of the ISS. He might be best known to the readers of Skeletal Radiology as the inventor of the widely used Bonopty ${ }^{\circledR}$ biopsy system. Dr. Astrom has been a strong supporter of Skeletal Radiology as a member of the editorial board and as author of dozens of perceptive and helpful reviews. We look forward to working with him in the years ahead.

Mark Kransdorf, MD

Daniel Rosenthal, MD

Bonopty is a registered trademark of AprioMed AB Virdings Allé 28 SE75450 Uppsala, Sweden

Daniel I. Rosenthal

dirosenthal@partners.org

Mark J. Kransdorf

kransdorf.mark@mayo.edu

1 Mayo Clinic, Phoenix, AZ, USA

2 Massachusetts General Hospital, Boston, MA, USA 